\title{
THE FAST/SKA SITE SELECTION IN GUIZHOU PROVINCE *
}

\author{
B. ZHU and Y. NIE \\ LARSIS, Institute of Remote Sensing Applications, Chinese Academy of Sciences, China \\ R. NAN and B. PENG \\ Beijing Astronomical Observatory, National Astronomical Observatories, China
}

\begin{abstract}
Many karst depressions with diameters of $300 \mathrm{~m}$ to $500 \mathrm{~m}$, suitable for constructing Arecibo-style radio telescopes, were identified in the south of Guizhou Province by Remote Sensing (RS) and Geographic Information System (GIS) technologies together with field investigations. Fundamental topography and landform databases were established for 391 candidate depressions, and using GIS the 3-dimensional images of depressions, at a scale of 1:10000, were then simulated to fit a spherical antenna.
\end{abstract}

Keywords: FAST, karst depression, site selection

\section{Geographical Conditions}

The Square Kilometer Array (SKA) is a proposed radio telescope with a collecting area of $1 \mathrm{~km}^{2}$. There are various concepts for realizing the SKA; one concept is an array of FAST-style antennas. FAST (Five hundred-meter Aperture Spherical Telescope; Peng et al., 2000) employs a large spherical reflector in which the surface is actively deformed into the parabola required to observe a target source. Karst landforms are critical for the construction of FAST; the karst depressions should be $500 \mathrm{~m}$ in diameter, corresponding to an opening angle of about 120 degrees in a sphere of radius $300 \mathrm{~m}$. The cost of building FAST will be minimised by finding the most suitable site.

Guizhou is located in the southwest of China and lies in the subtropical humid monsoon area, covering an area of approximately $170,000 \mathrm{~km}^{2}$, at longitudes between $103^{\circ} 36^{\prime}$ and $109^{\circ} 36^{\prime} \mathrm{E}$, and latitudes between $24^{\circ} 35^{\prime}$ and $29^{\circ} 09^{\prime} \mathrm{N}$ (see Figure 1). The annual average temperature is about $15^{\circ} \mathrm{C}$, and the annual precipitation $1100 \mathrm{~mm}-1400 \mathrm{~mm}$. The climate in Guizhou is mild with few days of frost and snow.

The topographical features of this general area are characterised by a plateau in Guizhou, with a transition to hills in neighboring Guangxi province (Figure 1). Due to the very thick deposits of carbonate rock, the influence of geological tectonics, climate and hydrological networks, karst landforms are well developed only in the transitional region. The area of karst landforms covers over $70 \%$ of Guizhou

* Supported by National Natural Science Foundation of China. 


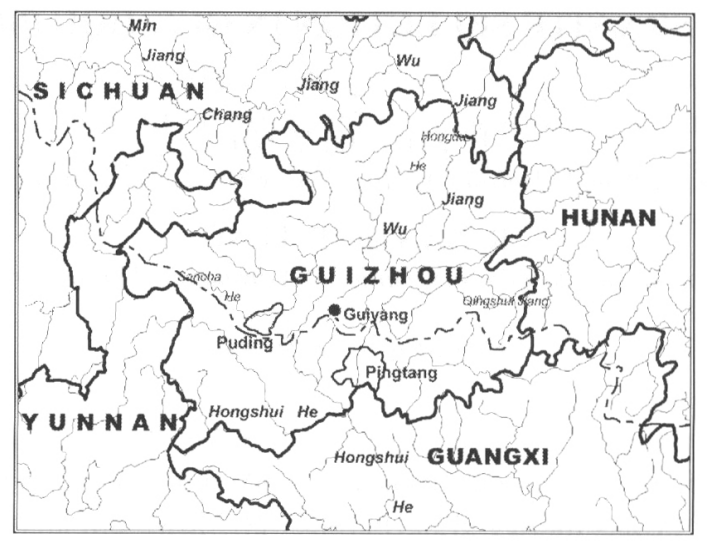

Figure 1. Sketch of siting area.
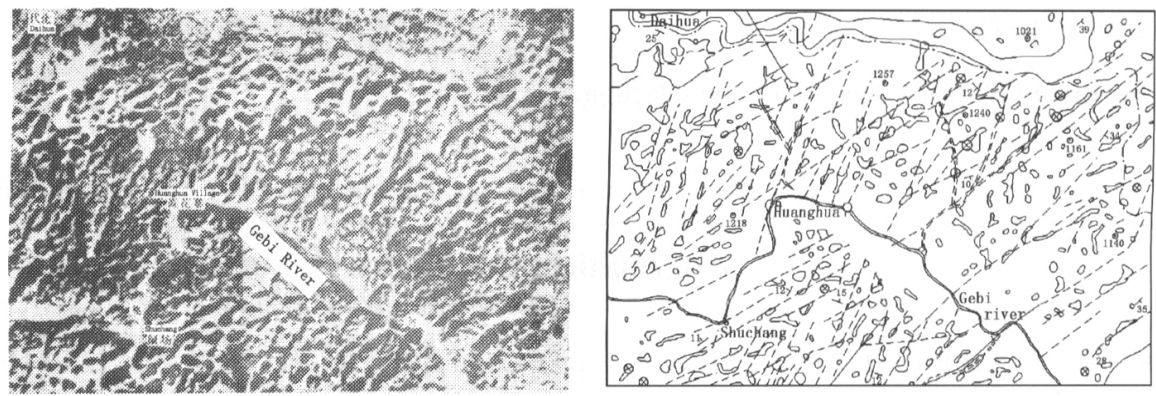

Figure 2. a) $\mathrm{B} / \mathrm{W}$ aerial photo Gebi river area $(12 \times 8 \mathrm{~km})$; b) Interpretation of the $\mathrm{B} / \mathrm{W}$ aerial photo.

province. The development of karst landforms is contingent on lithological properties, geological structure and the hydrographic network.

In the south of Guizhou, the sedimentary rock is nearly $10 \mathrm{~km}$ thick, and soluble carbonate rock contributes about $65 \%$ of the total thickness. The carbonate rock group ranges from Triassic to Cambrian. The lithological characteristics are suitable for karst landform development in southern Guizhou.

At the end of the Mesozoic Era, the Yanshan movement - caused by a collision of the East edge of the Eurasian plate with the Pacific plate - led to strong folding and breaking of the Earth's surface. This created a basically North-South geological structure, combining with Northeast, Northwest and North-North-East, and nearly East-West arc-like tectonics. All these effects induced karst development in the South of Guizhou. In addition, the multiphase tectonic activity formed well-developed tectonic joints, especially large-scale joints in carbonate rock in the region, which can be clearly seen in satellite images and aerial photos, as in Figure 2.

The network of rivers in Guizhou belongs to the Yangtze (north of dotted line in Figure 1) and Pearl River (south of dotted line in Figure 1) systems, while tributar- 


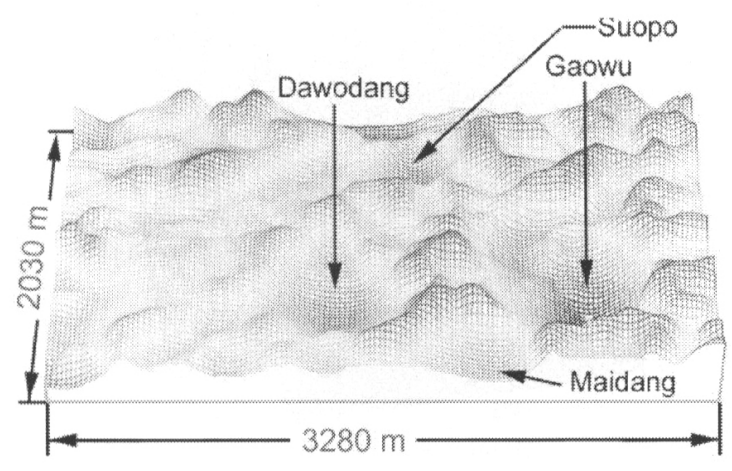

Figure 3. 3-D image of depressions in Liushui.

ies are distributed along $\mathrm{S}-\mathrm{N}$ geological structure. The development of karst landform was dependent on hydraulic gradients. Because of the low hydraulic gradients, karst hills and depressions are most developed around Miaoling. In downstream areas, there are higher hydraulic gradients (about $0.8-1.3 \%$ ) which created $\mathrm{U}$-shaped deep depressions and many canyons. Finally, in the middle reaches, down-cutting has a similar rate to side-cutting, because of the modest hydraulic gradient (about $0.4 \%$ ). U-shaped shallow depressions are widely distributed in this area. These shallow depressions (Figure 3) with diameters of $250 \mathrm{~m}$ to $800 \mathrm{~m}$ and depths of $150 \mathrm{~m}$ to $250 \mathrm{~m}$, are the best candidates for siting FAST, or an SKA employing FAST-style antennas.

In summary, a thick carbonate rock deposit, the gentle geological structure, large-scale tectonic joints together with the effects of neotectonism made karst depressions develop extensively in south Guizhou. These karst depressions would be suitable for building the FAST and the SKA.

\section{Hydrologic and Engineering Geology}

Subject to the local topography, regional main rivers have hydrological characteristics of few branches, steep slope, high flow velocity, and salient dynamic change. The depth of the groundwater, ranging from $50 \mathrm{~m}$ to $200 \mathrm{~m}$, is closely related to the river cutting degree of the Earth's surface. In this region, underground rivers are well fed by abundant groundwater.

Apart from the Quaternary residual material in basins, the rock group of engineering geology consists of solid carbonate rock and hard sandstone. Buildings in Guizhou have never been destroyed by natural geological disasters (Peng et al., 1996). The funnels and silos at the bottom of depressions are connected with karst underground channels. This is very helpful in ensuring that a FAST/SKA antenna 


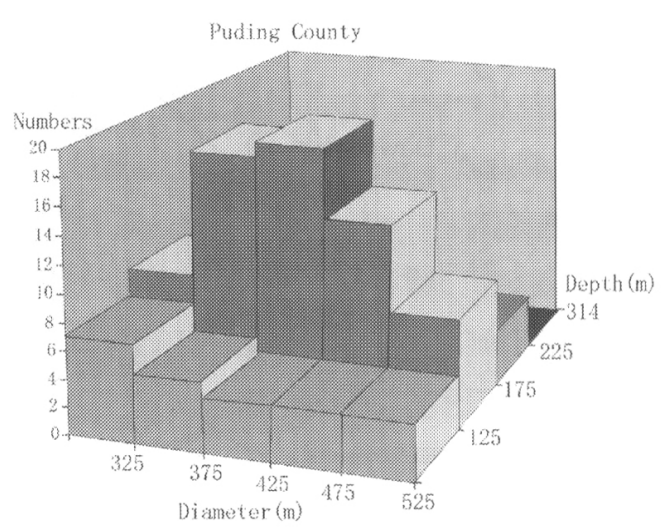

Figure 4. Karst depressions in Puding County.

will not be flooded. The neotectonism in the region is a large-scale differential lift, there is no measurable earthquake activity: the geological condition is stable.

The karst depressions in pre-selected areas have projected circular and polygonal shapes, with sides sloping by $25^{\circ}$ to $40^{\circ}$. These depressions are well developed, with solid rock walls and without bad geological phenomena.

\section{Depression Database and Engineering Simulation}

Based on 1:25,000 aerial photographic images and 1:10,000 topographic maps, 391 depressions were selected to be candidate sites for FAST/SKA using GIS, by the criteria: a) the major-to-minor axis ratio must be less than 1.5 , and the depression must be surrounded by least three hills; b) a minimum of $300 \mathrm{~m}$ in diameter and $100 \mathrm{~m}$ in depth. The database provides information including long axis orientation; major-to-minor axis ratio; depth of depression; number of surrounding hills; diameter; geographical coordinates; and altitude of the peak. Figure 4 shows some of the statistical results (Peng et al., 1997).

The geometry of karst depressions limits the efficiency of astronomical observations and the engineering cost of a FAST/SKA unit. Therefore the best site for building a FAST/SKA antenna must make use of the natural geometry of the depression, to minimize the engineering digging and filling of earth and stone. By combining GIS technology with image processing, 15 karst depressions were analyzed at a scale of 1:10,000. Under Arc/Info (GIS software, developed by ESRI, USA) and ILWIS (Integrated Land-use and Water Resources Information System) vector software, digital topographic maps, with edited and interpolated contours, we produced Digital Terrain Models (DTM) (Chen et al., 1998). Based on the DTM, relative elevation data was classified and overlaid with the DTM grid (Figure 5), then a 3-D karst depression can be mapped. The maximum effective diameter for the antenna in a depression could be decided by simulation of a dynamic 


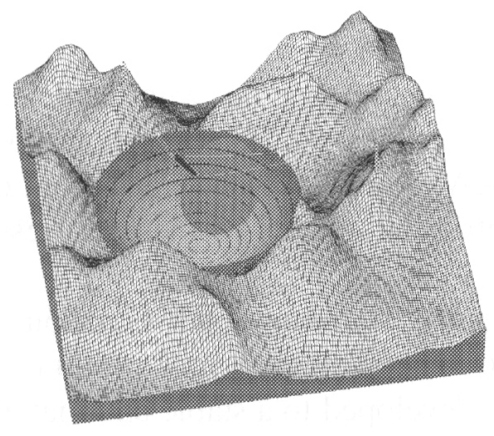

Figure 5. Model of a FAST/SKA antenna.

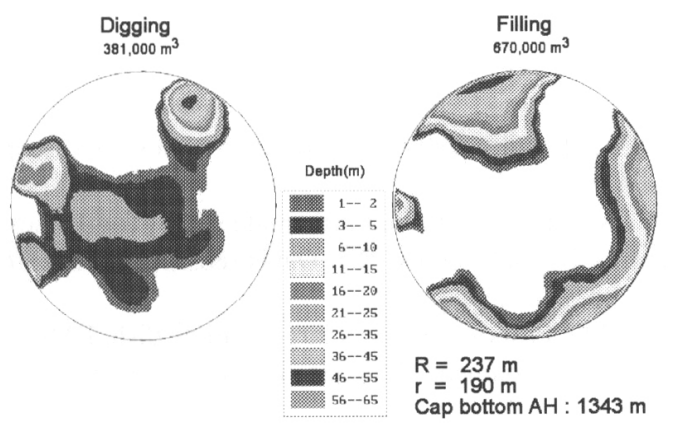

Figure 6. Quantities of digging and filling in Shangjiacong.

antenna in the depression setting. Furthermore, the amount of digging and filling of earth and stone can also be derived (Figure 6).

For different engineering objectives, the data and images above can be processed and displayed in various ways, other models can also be added to the data.

\section{Discussion and Concluding Remarks}

1. To meet the requirements of the SKA, most of the antennas must be concentrated within a region of diameter $50 \mathrm{~km}$. We used the HAZI module of the CALTECH-VLBI software package to simulate the $u, v$ coverage of 40 antennas (Peng et al., 1996). In a simulated observation of $0221+276$, with maximum zenith angle of $35^{\circ}$, a tracing mode was successfully applied to analyze 28 of 40 depressions, which form a relatively compact group in an area with a diameter of roughly $50 \mathrm{~km}$. 
2. In the middle reaches of rivers in southern Guizhou, a large number of karst depressions were developed in geological history. Their projected planar geometric shapes are circular and polygonal with diameters of $250-800 \mathrm{~m}$, depths of $150-250 \mathrm{~m}$ and slope angles of $25^{\circ}-40^{\circ}$. About 40 depressions, being best suited to the FAST/SKA project, can be selected out of all depressions in the Database. The geometric parameters of these depressions seem to meet the requirements of SKA.

3. The geological structure is stable in south Guizhou without any earthquake damage or active faults. The geological rock group is quite solid and the karst depressions there have developed to a stable and mature stage.

4. The water level of the groundwater ranges from $50 \mathrm{~m}$ to $200 \mathrm{~m}$. Generally, karst depressions have channels connected to the underground water and do not flood in rainy seasons. Furthermore, the groundwater is not corrosive.

\section{References}

Peng, B. and Nan, R.: 1997, Kilometer-square Area Radio Synthesis Telescope KARST Project, IAU Symposium 179, 93-94.

Peng, B., Nan, R., Qiu, Y., Nie, Y. et al.: 1996, Further site survey for the next generation large radio telescope in Guizhou, in: N. Jackson and R.J. Davis (eds.), High-Sensitivity Radio Astronomy, Cambridge Uni. Press, pp. 278-281.

Peng, B., Nan, R., Su, Y.: 2000, Proposed world's largest single dish, FAST, SPIE, 4015, 45.

Chen, X. et al.: 1998, Digital Environment Model Study Based on GIS, J. Rem. Sens. 2(4), 305-309. 